\title{
Erratum to: A Mechanism to Explain Ototoxicity in Neonates Exposed to Bumetanide: Lessons to Help Improve Future Product Development in Neonates
}

\author{
Karel Allegaert $^{1,2}$ (D) Amir $\operatorname{Lahav}^{3} \cdot$ John N. van den Anker ${ }^{1,4,5}$
}

Published online: 24 September 2016

(c) Springer International Publishing Switzerland 2016

\section{Erratum to: Pediatr Drugs}

DOI 10.1007/s40272-016-0190-4

In the original publication, the word "Bumetanide" in the article title is spelt incorrectly. It has been corrected in this erratum. The short title of the article (running head), which previously read as "Bumetanide and otoxicity" should read as "Bumetanide and ototoxicity".

The online version of the original article can be found under doi:10.1007/s40272-016-0190-4.

Karel Allegaert

karel.allegaert@uzleuven.be

Intensive Care and Department of Surgery, Erasmus MC-Sophia Children's Hospital, Rotterdam, The Netherlands

2 Department of Development and Regeneration, KU Leuven, Louvain, Belgium

3 Department of Pediatrics, Mass General Hospital for Children, Harvard Medical School, Boston, MA 02114, USA

4 Division of Paediatric Pharmacology and Pharmacometrics, University of Basel Children's Hospital, Basel, Switzerland

5 Division of Clinical Pharmacology, Children's National Health System, Washington, DC, USA 